\title{
BIMBINGAN TEKNIS FASILITATOR TEKNIK DALAM UPAYA PERCEPATAN REHABILITASI DAN REKONSTRUKSI PASCA GEMPA LOMBOK SUMBAWA
}

\author{
Siti Nurul Hijah ${ }^{1)}$ \\ ${ }^{1)}$ Fakultas Teknik Program Studi Teknik Sipil Universitas Islam Al-Azhar Mataram \\ e-mail:nurulhijah@yahoo.com
}

\begin{abstract}
Abstrak
Serangkaian gempabumi telah mengguncang Lombok pada tanggal 29 Juli (M6.4), 5 Agustus (M7.0) dan 19 Agustus 2018 (M6.9). Akibat dari gempa tersebut telah menimbulkan 567 orang meninggal, lebih dari 2000 orang mengalami luka-luka dan 445.343 jiwa harus mengungsi. Kerusakan terjadi pada infrastruktur dan perumahan sehingga aktifitas masyarakat dan penduduk setempat mengalami kelumpuhan. Upaya yang dilakukan oleh pemerintah adalah melakukan Rehabilitasi dan Rekonstruksi pasca bencana gempa.

Dalam rangka mendukung upaya percepatan Rehabilitasi dan Rekonstruksi pasca Gempa Lombok Sumbawa, perlu dilakukan bimbingan teknis kepada para fasilitator teknik pendamping masyarakat dengan tujuan untuk memberikan wawasan pengetahuan tentang bagaimana mekanisme pembuatan Rumah Tahan Gempa dengan menerapkan kaidah-kaidah teknik yang telah ditetapkan dan tidak keluar dari specifikasi dan aturan yang ditentukan.

Pelaksanaan bimbingan teknis diisi dengan pemberian materi yang didesain untuk memberikan informasi dan keahlian sehingga fasilitator teknik mampu menyelenggarakan program Rumah Tahan Gempa (RTG) yang bermutu dan berdampak terhadap Rehabilitasi dan Rekonstruksi pembangunan khususnya yang terkait dengan program pembangunan kembali rumah-rumah warga yang hancur akibat Gempa Lombok - Sumbawa yang terjadi pada tahun 2018.
\end{abstract}

Kata Kunci : Fasilitator, Teknik, Rehabilitasi, Rekonstruksi

\section{PENDAHULUAN}

Provinsi Nusa Tenggara Barat merupakan kawasan seismik aktif dan berpotensi diguncang gempa, hal ini terjadi dengan adanya serangkaian gempabumi telah mengguncang Lombok pada tanggal 29 Juli 2018 berkekuatan 6.4 Skala Richter, 5 Agustus berkekuatan 7.0 Skala Richter, 9 Agustus berkekuatan 5.9 Skala Richter dan sekitar 10 hari setelah gempa ketiga tepatnya 19 Agustus 2018, kembali dikejutkan dengan dua gempa berkekuatan lebih besar yaitu memiliki magnitudo 6,3 terjadi pada pukul 11.10 WIB dan magnitudo 7,0 terjadi pada pukul 21.56 WIB. Pada tanggal 25 Agustus 2018, gempa magnitudo 5,9 terjadi di timur Lombok atau lebih tepatnya di Sumbawa bagian barat. Gempa ini bisa dikatakan gempa ke-6 dari rangkaian Gempa Lombok yang magnitudonya lebih dari 5,5. Gempa-gempa susulan yang terjadi di Lombok baik yang dirasakan maupun tidak adalah lebih dari 2000 kejadian (Zulfakriza Z, 2018). Kejadiankejadian tersebut telah menimbulkan korban jiwa lebih dari 567 orang dan lebih dari 2000 orang mengalami luka-luka dan 445.343 jiwa harus mengungsi, sementara rumah yang mengalami kerusakan lebih dari 200 ribu dan hampir 850 fasilitas umum juga telah mengalami kerusakan, dengan perkiraan kerugian mendekati Rp 8 trilliun (BNPB, 2018).

Mengingat banyaknya fasilitas dan perumahan yang rusak, pemerintah melakukan upaya penanganan tanggap darurat, fasilitasi relawan dan bantuan kemanusiaan untuk menyiapkan tenda-tenda 
pengungsian untuk para korban gempa, mendirikan posko-posko bantuan, memulihkan trauma psikologis korban dan mengevakuasi korban gempa yang meninggal dunia maupun yang mengalami luka-luka serta melakukan penilaian terhadap semua fasilitas dan rumah yang rusak. Selanjutnya yang dilakukan oleh pemerintah adalah melakukan Rehabilitasi dan Rekonstruksi pasca bencana gempa untuk mengatasi pemenuhan kebutuhan rumah yang sangat tinggi dengan penyediaan perumahan yang cepat dan berkualitas baik (layak) sesuai Standar Nasional Indonesia (SNI). Pelaksanaan perbaikan rumah yang rusak karena gempa bumi dilaksanakan secara terintegrasi dan menggunakan sumber daya secara komperehensif yang didampingi oleh Satgas kementerian PUPR melalui tim fasilitator. Agar tujuan tersebut dapat terwujud Pemerintah Provinsi merekrut fasilitator untuk pendampingan masyarakat dalam membangun kembali infrastruktur yang mengalami kerusakan. Tim fasilitator melaksanakan kegiatan pendampingan Pokmas selama proses perbaikan rumah yang meliputi perencanaan, pelaksanaan konstruksi rumah tahan gempa dan administrasi pelaporan, memberikan pendampingan teknis dalam proses konstruksi rumah sesuai dengan kaidah teknis yang berlaku.

Berdasarkan hal tersebut diatas, mempertimbangkan latar belakang dan disiplin ilmu para fasilitator perlu dilakukan bimbingan teknis kepada para fasilitator teknik pendamping masyarakat dalam upaya penanganan Rehabilitasi dan Rekonstruksi dibidang perumahan dan permukiman yang dilaksanakan oleh pemerintah Nusa Tenggara Barat pasca gempa secara swakelola oleh masyarakat dengan asas efisiensi, efektifitas dan akuntabilitas.

\section{Maksud}

Maksud pelaksanaan Bimbingan Teknik untuk memberikan wawasan pengetahuan para peserta tentang bagaimana mekanisme pembuatan Rumah Tahan Gempa dengan menerapkan kaidah-kaidah teknik yang telah ditetapkan guna mendukung kegiatan Rehabilitasi dan Rekonstruksi pasca Gempa Lombok-Sumbawa, agar dapat bermanfaat bagi kepentingan masyarakat penerima bantuan rumah tahan gempa. Diharapkan dengan Bimbingan Teknis ini para fasilitator mampu melakukan self assessment dengan pemeriksaan secara menyeluruh terhadap pembangunan rumah tahan gempa agar tidak keluar dari specifikasi dan aturan yang ditentukan.

\section{Tujuan}

Memberikan pemahaman agar mampu menghasilkan wawasan pengetahuan tentang rumah tahan gempa dan mampu melaksanakan evaluasi dampak kegiatan rehabilitasi dan rekonstruksi sehingga para fasilitator teknik menjadi lebih siap dalam proses rehabilitasi dan rekonstruksi baik dalam perencanaan, perancangan dan pelaksanaan pembangunan Rumah Tahan Gempa.

\section{METODE PELAKSANAAN}

Kegiatan Bimbingan Teknis ini dilaksanakan dalam bentuk pemberian materi dan praktek lapangan yang didesain untuk memberikan informasi dan keahlian sehingga peserta mampu menyelenggarakan program Rumah Tahan Gempa (RTG) yang bermutu dan berdampak terhadap Rehabilitasi dan Rekonstruksi pembangunan khususnya yang terkait dengan program pembangunan kembali rumah-rumah warga yang hancur akibat Gempa Lombok - Sumbawa antara lain:

a. Pelaksanaan persiapan Bimbingan Teknis.

b. Menyiapkan program Bimbingan Teknis bertema Membangun Nusa Tenggara Barat Bangkit yang Mandiri dengan Konstruksi Rumah Tahan Gempa.

c. Impact Evaluation

d. Managing Various Stake Holders dalam Kegiatan Bimbingan Teknis

e. Memaksimalkan Penggunaan Teknis Rumah Tahan Gempa sebagai proses rehabilitasi dan rekonstruksi pasca Gempa

f. Peserta Bimbingan Teknis diikuti oleh 1300 (seribu tiga ratus) orang peserta dan dilaksanakan selama 16 (enam belas) JPL 
atau 2 (dua) hari di tujuh kabupaten yang terkena dampak gempa yaitu Kota Mataram, Kabupaten Lombok Barat, Lombok Utara, Lombok Tengah, Lombok Timur, Sumbawa Barat dan Sumbawa Besar.

g. Setelah Bimbingan Teknis selesai para fasilitator mampu mendampingi masyarakat dalam melakukan pembangunan rumah tahan gempa.

Tabel 1. Jadwal Acara Kegiatan Bimtek Rumah Tahan Gempa Rehabilitasi Dan Rekonstruksi Pasca Gempa Lombok-Sumbawa Kab. Lombok Utara-NTB

Aula SMAN 1 Tanjung (Kelas A) Kantor Desa Jenggala (Kelas B) Gedung Family Store Lapangan Gondang (Kelas C)

Sabtu, 23 Februari 2019

\begin{tabular}{|c|c|c|}
\hline $\begin{array}{l}\text { Waktu } \\
\text { (Wita) }\end{array}$ & Materi & PIC \\
\hline 08.00 & Registrasi & Panitia \\
\hline - & Peserta & \\
\hline \multicolumn{3}{|l|}{08.3} \\
\hline \multicolumn{3}{|l|}{0} \\
\hline 08.30 & Pembukaan: & \\
\hline- & Menyanyika & \\
\hline 09.3 & $\mathrm{n} \quad$ Lagu & \\
\hline \multirow[t]{19}{*}{0} & Indonesia & \\
\hline & Raya & \\
\hline & Pembacaan & \\
\hline & Do’a & \\
\hline & Sambutan & \\
\hline & Kepala Balai & \\
\hline & Penerapan & \\
\hline & Teknologi & \\
\hline & Konstruksi & \\
\hline & Sambutan & \\
\hline & Ketua & \\
\hline & LPJKP NTB & \\
\hline & Sambutan & \\
\hline & Komandan & \\
\hline & resort militer & \\
\hline & (Danrem) & \\
\hline & (Sekaligus & \\
\hline & Membuka & \\
\hline & Acara) & \\
\hline \multirow{4}{*}{$\begin{array}{r}09.30- \\
12.00\end{array}$} & Teknologi & \\
\hline & Rumah & Narasumbe \\
\hline & Instan & $\mathrm{r}$ \\
\hline & Sederhana & \\
\hline
\end{tabular}

Sehat

(RISHA)-

(kelas A)

Teknologi

Rumah

Instan

Struktur

Baja

(RISBA)-

(Kelas B)

Teknologi

Rumah

Domus-

(Kelas C)

12.00

- ISHOMA

13.00

13.00 Teknologi

Rumah

15.1 Instan

5 Struktur

Baja

(RISBA)-

(Kelas A)

Teknologi

Rumah

Domus-

(Kelas B)

Teknologi

Rumah

Instan

Sederhana

Sehat

(RISHA)-

(kelas C)

15.15 Teknologi

Rumah

17.3 Domus-

0 (Kelas A)

Teknologi

Rumah

Instan

Sederhana

Sehat

(RISHA)-

(kelas B)

Teknologi

Rumah

Instan

Struktur

Baja

(RISBA)-

(Kelas C)

Minggu, 24 Februari 2019

Lingkungan Hidup dan Bencana
Narasumbe $\mathrm{r}$

Narasumbe

$r$ 


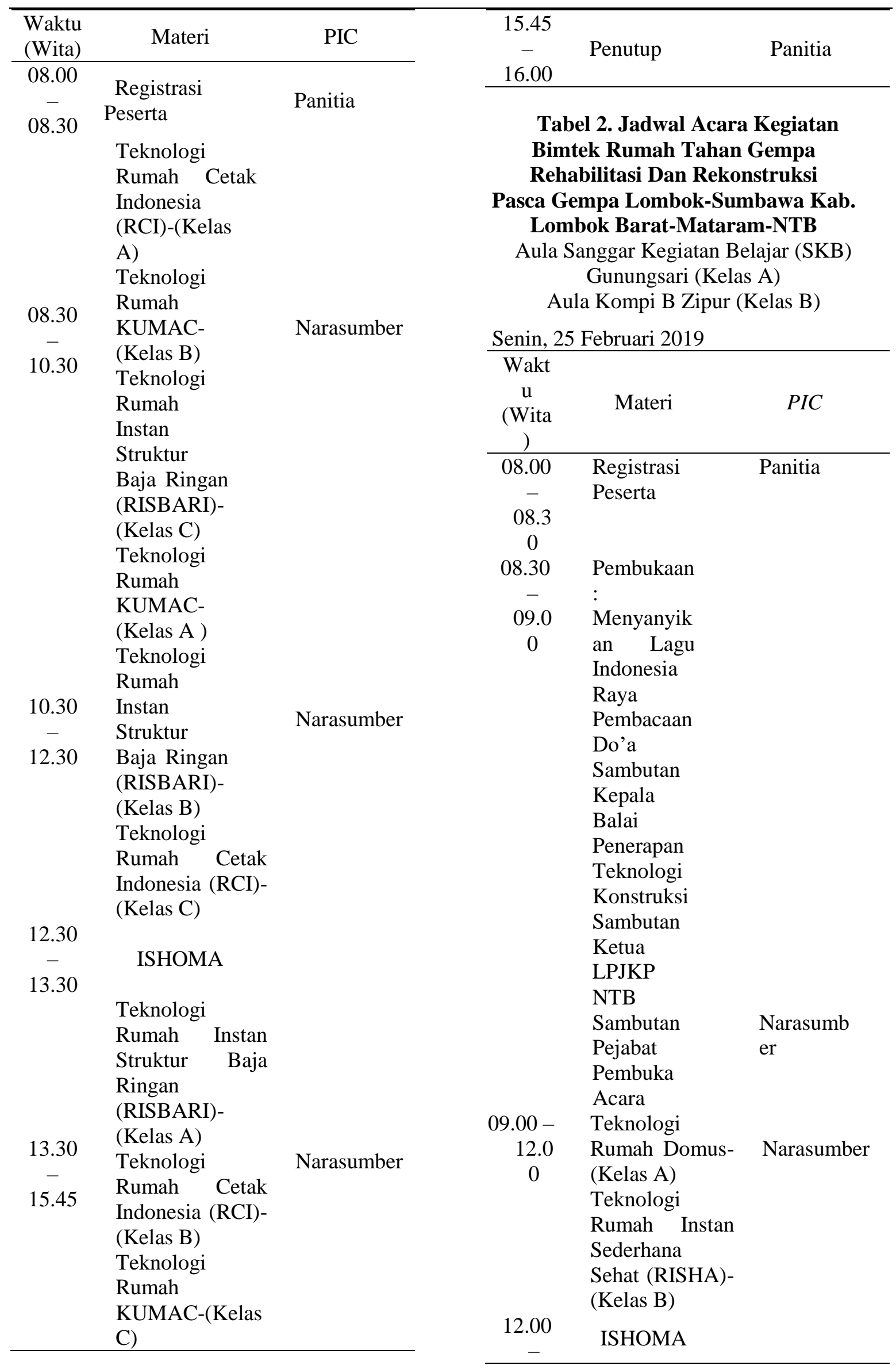




\begin{tabular}{cll}
\hline 13.0 & & \\
0 & & \\
13.00 & Teknologi & \\
- & Rumah Instan & \\
15.0 & Struktur Baja & \\
0 & Ringan & Narasumber \\
& (RISBARI)- & \\
& (Kelas A) & \\
& Teknologi & \\
& Rumah Domus - & \\
& (kelas B) & \\
15.00 & Teknologi & \\
- & Rumah Instan & \\
17.0 & Sederhana & \\
0 & Sehat (RISHA)- & \\
& (Kelas A) & \\
& Teknologi & Narasumber \\
& Rumah Instan & \\
& Struktur Baja & \\
& Ringan & \\
& (RISBARI)- & \\
& (Kelas B) & \\
\hline
\end{tabular}

Selasa, 26 Februari 2019

\begin{tabular}{|c|c|c|}
\hline $\begin{array}{l}\text { Waktu } \\
\text { (Wita) }\end{array}$ & Materi & PIC \\
\hline $\begin{array}{c}08.00- \\
08.30\end{array}$ & $\begin{array}{l}\text { Registrasi } \\
\text { Peserta }\end{array}$ & Panitia \\
\hline $\begin{array}{c}08.30- \\
10.30\end{array}$ & $\begin{array}{l}\text { Teknologi } \\
\text { Rumah Cetak } \\
\text { Indonesia } \\
\text { (RCI)-(Kelas } \\
\text { A) } \\
\text { Teknologi } \\
\text { Rumah } \\
\text { KUMAC- } \\
\text { (Kelas B) }\end{array}$ & Narasumber \\
\hline $\begin{array}{c}10.30- \\
12.30\end{array}$ & $\begin{array}{l}\text { Teknologi } \\
\text { Rumah Instan } \\
\text { Struktur Baja } \\
\text { (RISBA)- } \\
\text { (Kelas A) } \\
\text { Teknologi } \\
\text { Rumah Cetak } \\
\text { Indonesia } \\
\text { (RCI)-(Kelas } \\
\text { B) }\end{array}$ & Narasumber \\
\hline $\begin{array}{c}12.30- \\
13.30\end{array}$ & ISHOMA & \\
\hline $\begin{array}{c}13.30- \\
15.45\end{array}$ & $\begin{array}{l}\text { Teknologi } \\
\text { Rumah } \\
\text { KUMAC- } \\
\text { (Kelas A) }\end{array}$ & Narasumber \\
\hline
\end{tabular}

\begin{tabular}{|c|l|l|} 
& \multicolumn{2}{|l|}{ Teknologi } \\
& $\begin{array}{l}\text { Rumah Instan } \\
\text { Struktur Baja } \\
\text { (RISBA)- } \\
\text { (Kelas B) }\end{array}$ & \\
\hline $\begin{array}{c}15.45- \\
16.00\end{array}$ & Penutup & Panitia \\
\hline
\end{tabular}

\section{HASIL DAN PEMBAHASAN}

Pelaksanaan perbaikan rumah korban bencana gempa agar berjalan dengan profesional, efektif dan efisien kegiatan bimbingan teknis tentang teknis konstruksi rumah tahan gempa maupun teknik fasilitasi masyarakat dilaksanakan selama dua hari dimasingmasing kabupaten/kota dengan memberikan materi model rumah tahan gempa yang telah direkomendasikan oleh Kementerian PUPR melalui Puskim balitbang dan Dinas Perumahan dan Permukiman Prov. NTB diantaranya adalah Rumah Tahan Gempa (RTG) : Rumah Instan Sederhana Sehat (RISHA), Rumah Instan Konvensional (RIKO), Rumah Instan Kayu (RIKA), Rumah Cetak Indonesia (RCI), Rumah Instan Struktur Baja (RISBA), Rumah Instan Struktur Baja Ringan (RISBARI), DOMUS, Rumah Kuat, Mudah, Aman, Cepat (KUMAC), Rumah Instan Sehat Tahan Gempa (RISTA), Rumah Instan Tahan Gempa Al-Ansar (RITA) dan Rumah Instan Sehat Galvanis Tahan Gempa (RISGA) dengan rata-rata luasan $36.00 \mathrm{~m}^{2}$ dan 30,00 $\mathrm{m}^{2}$. Total pelaksanaan bimbingan teknis yang telah dilaksanakan di tujuh kabupaten/kota selama 12 (dua belas) hari, diikuti 1300 (seribu tiga ratus) orang peserta dari tujuh kabupaten/kota dengan jadwal pelaksanaan kegiatan bimbingan teknis sebagai berikut :

Tabel 3. Jadwal Pelaksanaan Bimbingan Teknis Rumah Tahan Gempa Fasilitator Teknik (Personil TNI dan Sipil) Di Tujuh Kabupaten Se Provinsi Nusa Tenggara Barat

\begin{tabular}{ccccc}
\hline & & \multirow{2}{*}{ Tangga } & \multicolumn{2}{c}{ Jumlah } \\
N & Kabup & l & \multicolumn{2}{c}{ PNI } \\
\cline { 4 - 5 } o & aten & Pelaksa & SIP \\
naan & $\begin{array}{c}\text { (Yonzi } \\
\text { pur) }\end{array}$ & IL \\
\hline
\end{tabular}




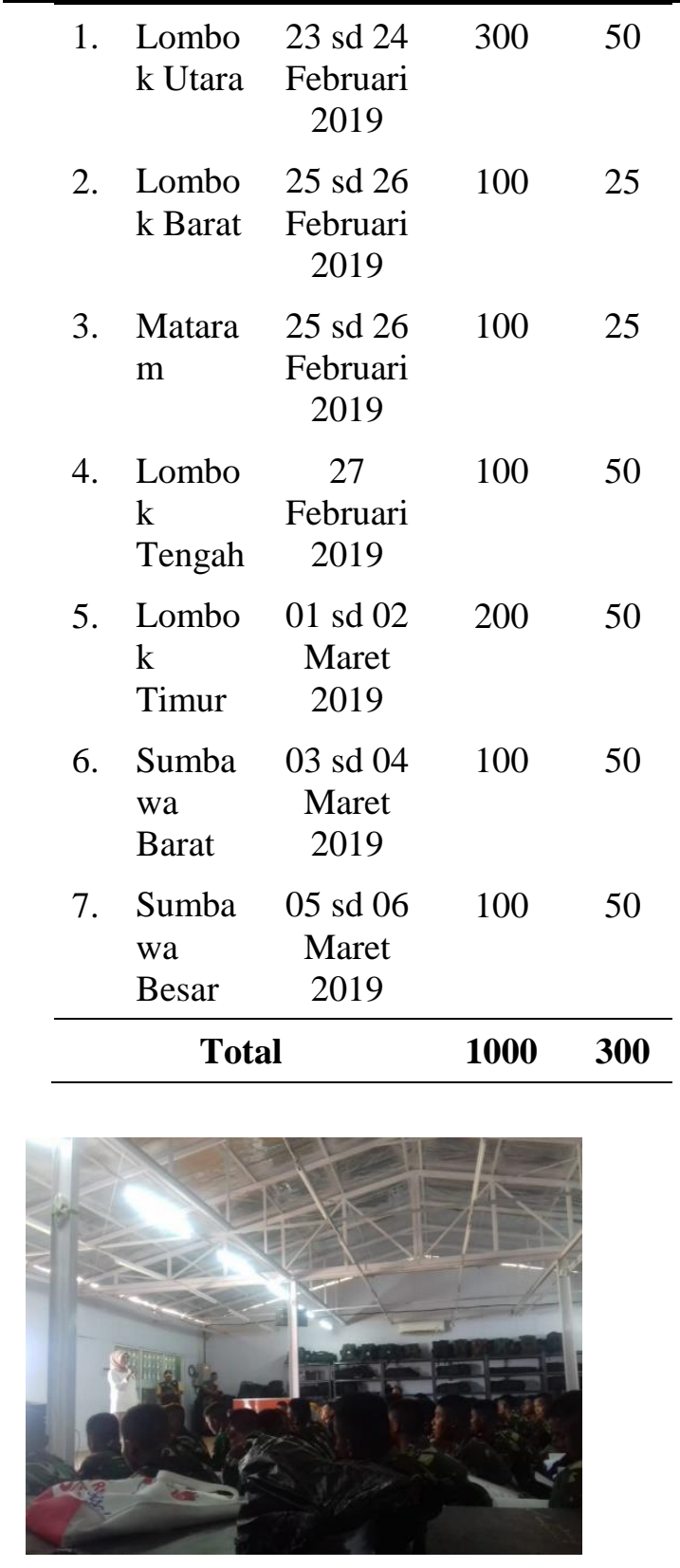

Gambar 1. Upacara Pelepasan Kegiatan Bimbingan Teknis Fasilitator Teknik

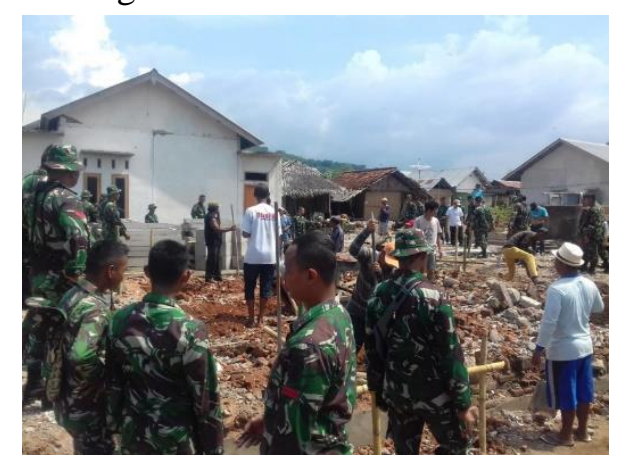

Gambar 2. Dokumentasi Kegiatan Bimbingan Teknis Fasilitator Teknik

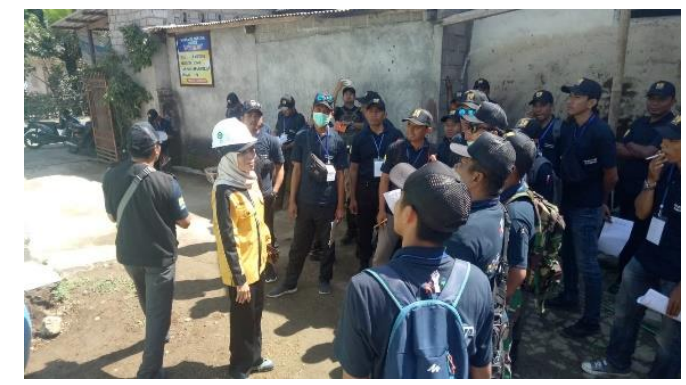

Gambar 3. Dokumentasi Pembekalan Bimbingan Teknis Fasilitator Teknik

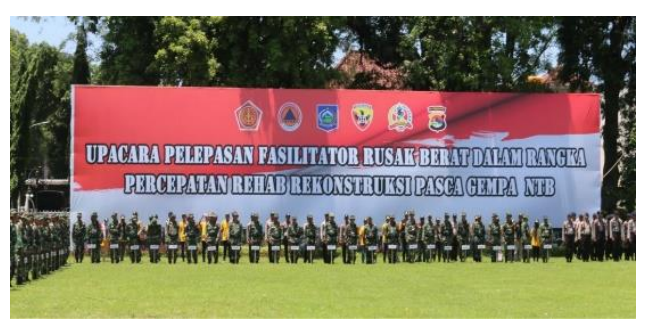

Gambar 4. Dokumentasi Praktek Lapangan Bimbingan Teknis Fasilitator Teknik

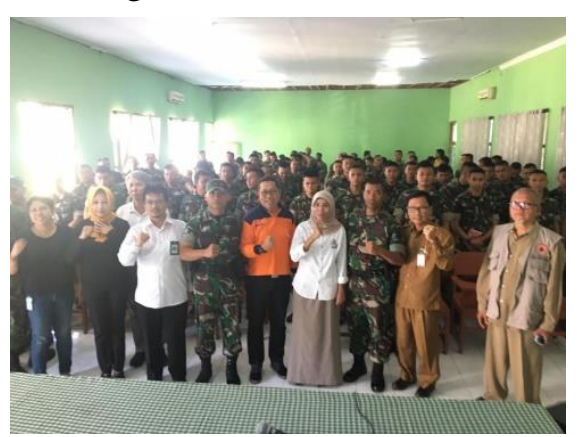

Gambar 5. Dokumentasi Praktek Lapangan Bimbingan Teknis Fasilitator Teknik

Dari hasil pelaksanaan kegiatan bimbingan teknis ini para fasilitator teknik mampu menguasai petunjuk praktis persyaratan bangunan tahan gempa dan mempraktekkannya dengan benar dilapangan, mampu mensinkronisasi antara petunjuk praktis dan praktek yang dibuktikan melalui praktek yang telah dilaksanakan dengan merancang dan memasang teknologi konstruksi bangunan rumah tinggal dengan komponen yang kompak dan berukuran modular serta menggunakan sistem bongkar pasang/knock down yang dapat disediakan secara pabrikasi.

Fasilitator teknik telah mampu mendampingi pokmas selama proses perbaikan rumah dan 
memberikan pendampingan teknis sesuai dengan kaidah teknis yang berlaku dalam menentukan model rumah berdasarkan alternatif yang tersedia, menyiapkan Dokumen Teknis Perbaikan Rumah (DTPR), menyusun rencana anggaran biaya (RAB) perbaikan rumah korban bencana yang efisien dan benar, menyusun rencana kerja pelaksanaan dan rencana pengadaan bahan perbaikan rumah korban serta melakukan pendampingan masyarakat dengan memfasilitasi kegiatan sosialisasi dan pelatihan dalam rangka penguatan kapasitas masyarakat, berkoordinasi dengan pokmas, tim pendamping masyarakat (TPM), BPBD Kabupaten/Kota dan OPD teknis terkait.

\section{KESIMPULAN DAN SARAN}

\section{Kesimpulan}

Setelah proses kegiatan bimbingan teknis fasilitator teknik selesai dan evaluasi dilaksanakan, dapat disimpulkan bahwa pelaksanaan bimbingan teknis berjalan dengan baik. Para peserta mampu meningkatkan kompetensi dan keahliannya dalam menguasai teori dan mempraktekkan pelaksanaan rumah tahan gempa dengan benar dilapangan.

Fasilitator teknik mampu mendampingi kelompok masyarakat dan menyelenggarakan program Rumah Tahan Gempa (RTG) yang bermutu dan berdampak terhadap upaya percepatan Rehabilitasi dan Rekonstruksi pembangunan khususnya yang terkait dengan program pembangunan kembali rumah-rumah warga yang hancur akibat Gempa Lombok Sumbawa yang terjadi pada tahun 2018.

\section{Saran}

Disiplin peserta perlu ditingkatkan, karena selama pelaksanaan bimbingan teknis masih ada beberapa peserta yang kurang disiplin waktu.

Dukungan pemerintah daerah dan kabupaten/kota serta masyarakat yang terkena bencana gempa agar berperan aktif dalam implementasi kegiatan rehabilitasi dan rekonstruksi baik secara langsung maupun tidak langsung.

\section{UCAPAN TERIMA KASIH}

Melalui kesempatan ini, penulis menyampaikan terima kasih dan penghargaan yang setinggi-tingginya kepada pemerintah kabupaten/kota sebagai tempat pelaksanaan kegiatan bimbingan teknis dan sebagai tempat praktek yang telah berperan aktif dalam mensukseskan kegiatan ini. Ucapan terima kasih juga kami sampaikan kepada Pemerintah Provinsi Nusa Tenggara Barat khususnya pada Dinas Perumahan dan Permukiman Prov. NTB, Komandan Resort Militer 162 Wirabakti NTB, BPBD Prov. NTB, Lembaga Pengembangan Jasa Konstruksi Prov. (LPJKP) NTB dan Universitas Islam Al-Azhar Mataram atas bantuan dan dukungannya sehingga pengabdian masyarakat dalam bentuk kegiatan bimbingan teknis dapat diselesaikan dengan baik.

\section{DAFTAR PUSTAKA}

Anonim, 2018. Petunjuk Pelaksanaan Bantuan Stimulan Perbaikan Rumah Korban Bencana Gempa Bumi di Provinsi Nusa Tenggara Barat. Badan Nasional Penanggulangan Bencana : Jakarta.

Muhammad Heri Zulfiar, Arman Jayady. 2018. Kajian Kerentanan Pada Sektor Konstruksi Dalam Pengurangan Resiko Bencana Gempa Bumi. Jurnal Karkasa Volume 4 No. 1, 2018 ISSN 2580-7595.

Tim Seismologi Teknik BMKG, 2018. Ulasan Guncangan Tanah Akibat Gempa Bumi Lombok Timur.

Theresita Herni Setiawan. 2007. Rehabilitasi dan Rekonstruksi Perumahan Korban Bencana Gempa Bumi dan Gelombang Tsunami Kabupaten Bireun Provinsi Nanggroe Aceh Darussalam. Jurnal Teknik Sipil, Volume IV No. 1 Januari 2007:01-19.

Zulfakriza Z. 2018. Melihat Kembali Gempa Lombok 2018 dan Sejarah Kegempaannya. Kompas.com, diakses tanggal 23 September 2018. 